\title{
DESIGNING OF RETAINING STRUCTURES OF REINFORCED SOIL WITH LIMIT CONDITIONS METHOD
}

The principles of limit conditions method in designing modern retaining structures of reinforced soil are presented. The principles are elaborated according to French Standard NF P 94-200 [1, 3]. Procedures of checking of particular kinds of stability are described. The most frequently adopted combinations of loads are given together with partial factors of safety of external, internal and general stability, method factors, friction factors of soil medium-reinforcement and values of partial safety factors of settlement.

\section{Initial remarks}

Dimensioning of retaining structures of reinforced soil elaborated by authors of this technology consists in the checking of internal and external stability $[2,5,6]$, applying safety factors of pretty high values $(1,5-3,15)$. The Standard [4] in which one of the chapters concerns dimensioning of retaining walls of reinforced soil, according to F. Schlosser $[2,5,6]$ is binding in Poland. The Standard also gives principles of approximate adoption of the active zone, which is important for design economy. Modern structures of reinforced soil should be designed with limit conditions method according to the new French Standard NFP 94-200 [1,3]. This Standard requires control of three types of stability of reinforced soil mass:

- external (because of slide along the base and bearing capacity of the ground),

- internal (because of value of the forces stretching reinforcement and anchoring bars in the soil),

- general, because of the possibility of slides along potential soil destruction surfaces due to cutting down.

The calculation scheme of reinforced soil structure is shown in Fig. 1 [1].

\section{External stability}

The structure is treated as uniform mass loaded with internal and external forces. Mass deadweight and water uplift pressure (when structure might be or is inundated with water) are internal loads. External loads include: thrust of backfill kept in balance by the reinforced mass as well as permanent and variable loads influencing the mass surcharge or its close proximity and passive earth pressure forces. The value of backfill thrust on the reinforced soil structure is calculated with conventional formulas (e.g. Coulomb's) assuming that the thrust influences theoretical surface located parallel to the structure lining, along the ends of longest reinforce-

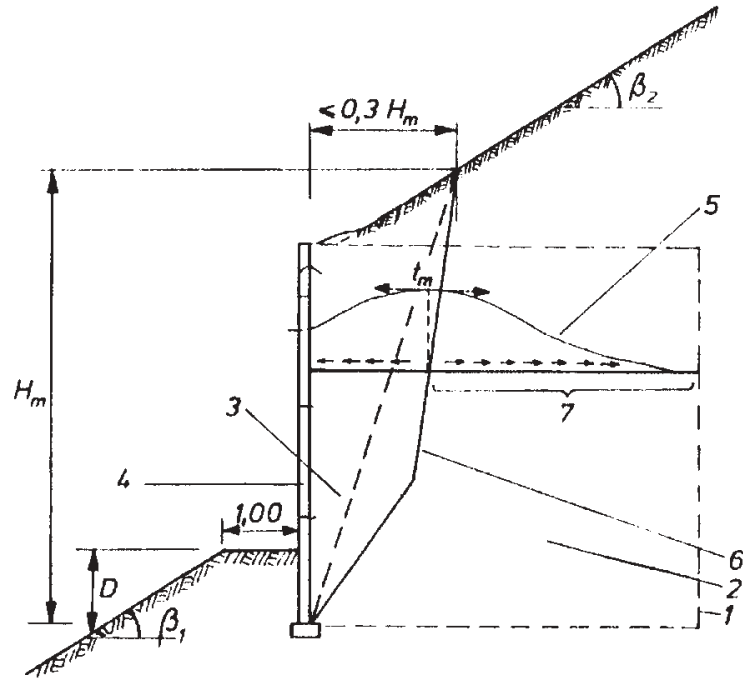

Fig.1. Calculation scheme of reinforced soil structure (according to [1, 3]): 1 - reinforced soil mass, 2 - bars anchoring zone, 3 - reinforced soil active zone, 4 - structure head lining, 5 - values of reinforcement element stretching, 6 - distribution of values of stretching along reinforcement, 7 - maximal stretching line, 8 - bar anchoring section

ment elements (Fig. 2). The tables of the NFP 94-200 [1, 3] standard include the most probable combinations of loads which are taken into account while checking external stability of the reinforced soil structure as well as partial safety factors $\gamma_{m}$.

Stability of the structure with regard to slide along the base will be ensured after fulfilling the following conditions:

$$
R_{h} \gamma_{F 3} \leq\left(R_{v} \operatorname{tg} \varphi_{1 k} / \gamma_{m \varphi}+L_{c 1 k} / \gamma_{c}\right)
$$

and

$$
R_{h} \gamma_{F 3} \leq\left(R_{v} \operatorname{tg} \varphi_{f k} / \gamma_{m \varphi}+L_{c f k} / \gamma_{c}\right)
$$

\footnotetext{
${ }^{*}$ Edward Hutnik ${ }^{1}$, Andrzej Surowiecki ${ }^{2}$

${ }^{1}$ Agricultural University in Wrocław, Institute of Building Engineering and Landscape Architecture, E-mail: hutnik@ozi.ar.wro.pl

${ }^{2}$ Wrocław Technical University, Institute of Civil Engineering; Agricultural Academy in Wrocław, Institute of Building Engineering and Landscape Architecture, E-mail: suran@poczta.pl
} 


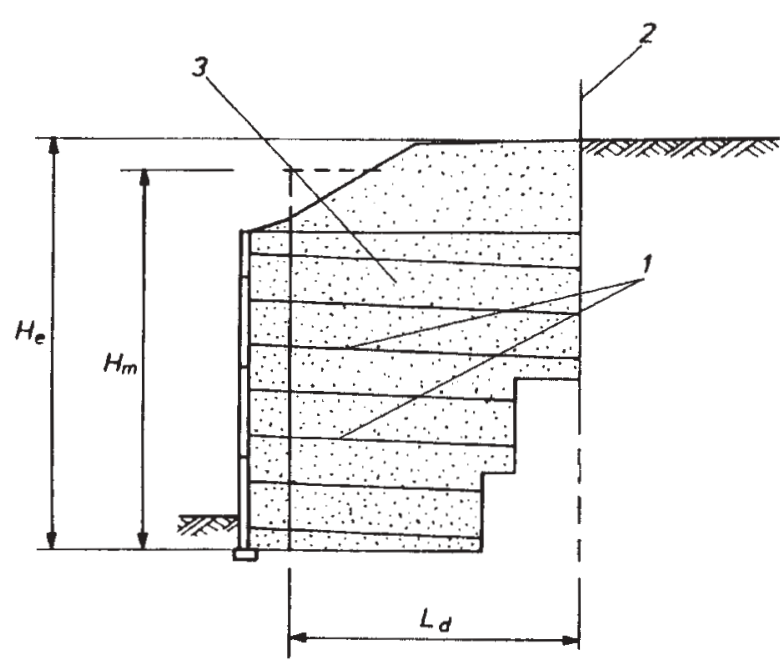

Fig. 2. Calculation scheme of soil backfill thrust [1, 3]: 1 - actual ends of reinforcement layers; 2 - line of reinforcement ends determining theoretical influence of the structure backfill thrust; 3 - zone of the internal active horizontal thrust

where:

$R_{h}, R_{v}$ - horizontal and vertical components of the resultant load in the base of reinforced soil structure, neglecting method factor $\gamma_{F 3}[\mathrm{kN} / \mathrm{m}$ along the lining],

$\varphi_{1 k}, c_{1 k}$ - characteristic values of the internal friction angle and soil cohesion in the reinforced mass [degrees; $\mathrm{kPa}$ ],

$\varphi_{f k}, c_{f k}$ - characteristic values of internal friction angle and subsoil soil cohesion [as above]

$L \quad$ - length of soil reinforcement layers (in structure with rectangular section), [m],

$\gamma_{F 3}-$ method factor,

$\gamma_{m \varphi} \quad$ - partial safety factor applied to the tangent of internal friction angle; in case of standard load combination is 1.20 ; in case of exceptional combination is 1.10 ;

$\gamma_{m c} \quad$ - partial safety factor applied to the effective cohesion; in case of standard load combination is 1.65 ; in case of exceptional combination 1.50 .

Soil resistance parameters corresponding to the effective parameters are determined from samples concentrated up to $95-100 \%$ (according to Proctor's standard optimum). When there are no study results, A. Jarominiak [1] recommends adoption - for the reinforced mass, not inundated with water: $\varphi_{1 k}=360, c_{1 k}=0$, $\gamma_{1 \text { mmin }}=18 \mathrm{kN} / \mathrm{m}^{3}, \gamma_{1 \text { max }}=20 \mathrm{kN} / \mathrm{m}^{3} ; \gamma_{1 \text { min }}, \gamma_{1 \text { kmax }}-$ minimal and maximal characteristic density of the reinforced mass.

Checking with regard to subsoil bearing capacity means fulfilling the following inequality:

$$
q_{r e f} \leq q_{f u} / \gamma_{m q}
$$

where:

$q_{f u} \quad$ - subsoil limit bearing capacity $[\mathrm{kPa}]$ $\gamma_{m q} \quad$ - partial safety factor of the reinforced mass subsoil bearing capacity, assumed as 1.50 ,

$q_{\text {ref }}=\gamma_{F 3} R_{v} /\left(L-2 M_{b} / R_{v}\right)$ - subsoil load with reinforced soil mass $[\mathrm{kPa}]$.

In case of structure with vertical front wall $L \leq H_{m}$ :

$R_{v}, L \quad$ - previously given designation,

$M_{b} \quad$ - resultant moment in the middle of the reinforced soil structure base, neglecting method factor $\gamma_{F 3},[\mathrm{kNm} / \mathrm{m}]$.

\section{Control of internal stability}

The aim of this control is to determine whether tension stresses in the reinforcement are within permissible range and whether anchoring resistance of the bars is respectively greater than forces pulling the reinforcement from the soil. The formula adopted for control of internal stability is shown in Fig. 3. It was determined based on theoretical analyses, model research and tests of reinforced soil structures.

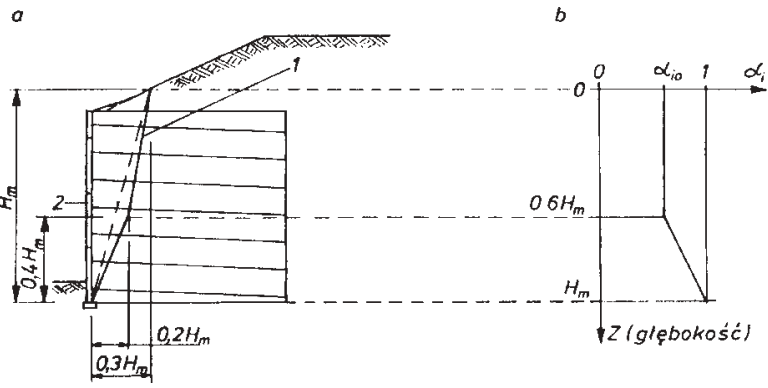

Fig. 3. Formula adopted for calculations of internal stability of the structure [1]: $a$ - location of maximal stretching lines, $b$ - change with depth of $\alpha_{i}$ factor, 1 - maximal stretching line, 2 - structure lining,

$$
z \text { - depth }
$$

The line of maximal soil reinforcement stretching is determined first. Maximal stretching for $1 \mathrm{~m}$. along the lining equals:

$$
t_{m}=\sigma_{h} s_{v} \quad[\mathrm{kN} / \mathrm{m}]
$$

where: $s_{v}$ - vertical spacing of reinforcement layers [m],

$$
\sigma_{h}=K \sigma_{v}+\sigma_{q h}-\text { maximal horizontal stress in the ana- }
$$
lyzed reinforcement layer (along the maximal stress line) caused by the weight of its overlay, $[\mathrm{kPa}]$

$K$ factor depends on the depth (z) of reinforcement layer location in the soil mass:

- when $z \leq z_{0}$ then $K_{z}=K_{a} \Omega_{1}\left[1.6\left(1-z / z_{0}\right)+z / z_{0}\right]$

- when $z \leq z_{0}$ then $K_{(z)}=K_{a} \Omega_{1}$

where:

$z_{0}=6 \mathrm{~m}$,

$K_{a}=\operatorname{tg}^{2}\left(0.25 \pi-0.5 \varphi_{1 k}\right)-$ active friction factor for the reinforced soil mass,

$\Omega_{1}-$ form factor, assumed 
$\Omega_{1}=1.0$ in case of soil reinforcement with bands (flat bars),

$\Omega_{1}=1.5$ in case of soil reinforcement with shells (e.g. geogrids).

Vertical stress $\sigma_{v}$ at $(z)$ level is determined similarly as in case external stability control, which means calculating the resultant loads (above the analyzed layer) and distributing them according to Meyerhoff principle for width $\left(L_{(z)}-2 e x\right)$. In case of vertical lining the following relationship is binding:

$$
\sigma_{v}(z)=R_{v}(z) /[L(z)-2 e x]+\sigma_{v q}
$$

in which:

$R_{v}(z)$ - resultant horizontal load $(z)[\mathrm{kN} / \mathrm{m}]$,

$L(z) \quad$ - horizontal length of reinforcement element (z) [m], ex $=M(z) / R_{v}(z)$

$M(z)$ - horizontal overturning moment $(z)$ in the middle of reinforcement layer; it is a resultant of all moments caused by loads applied above the level $(z)$, considering their distribution $[\mathrm{kNm} / \mathrm{m}]$,

$\sigma_{v q} \quad$ - vertical stress caused by loading the surcharge of the reinforced soil structure, considering distribution of this load $[\mathrm{kPa}]$.

When the reinforced soil structure is loaded with horizontal forces transverse to the lining (e.g. as a result of hydrostatic pressure or braking at the pavement ), then soil reinforcement stretching caused by these forces should be taken into account.

Stretching stress at the lining of the structure is calculated according to the following formula:

$$
t_{p}=\left(K \Sigma \alpha_{i} \sigma_{v i}+\sigma_{h q}\right) h_{a}
$$

where:

$K, h_{a} \quad$ - previously given,

$\alpha_{i} \quad$ - factor depending on flexibility of the lining and location of maximal stretching lines; its value changes corresponding to depth and in case of vertical linings it is (Fig. 3 b):

$\alpha_{i 0}=0.75$ - for very deformable linings (of metal and of geogrids, $\left.i_{f}=2\right)$,

$\alpha_{i 0}=0.85$ - for moderately deformable linings (of prefabricated concrete units, $i_{f}=1$ ),

$\alpha_{i 0}=1.00$ - for rigid linings (of concrete slabs with length identical with structure height, $i_{f}=0$ ),

$i_{f} \quad$ - lining rigidity factor,

$\sigma_{v i} \quad$ - vertical stress corresponding to function $\alpha_{i}$; for retaining structures equals $\alpha_{i}=1.0$; for abutments $\alpha_{i}=2.0$ $[\mathrm{kPa}]$.

Characteristic value of friction mobilized in each reinforcement layer is calculated according to the following formula:

$$
r_{f}=2 N b L_{a} \mu^{*} \sigma_{v}
$$

in which:

$N \quad$ - number of reinforcing elements for $1 \mathrm{~m}$ along the lining (in case of shell lining $N=1$ ); number 2 results from friction at the bottom and upper surface of the reinforcement $\left(2 b L_{a}\right)\left[\mathrm{m}^{2}\right]$,

$b \quad$ - width of reinforcement element (in case of shell lining $b=1)[\mathrm{m}]$,

$\mu^{*} \quad-$ real friction factor in the analyzed layer,

$L_{a} \quad$ - length of reinforcing element in the analyzed layer [m],

$\sigma_{v} \quad-$ mean vertical stress exerted on the analyzed reinforcement layer $[\mathrm{kPa}]$,

$\sigma_{v}=\left(1 / L_{a}\right)\left(\sigma_{v}(x) d x\right.$

$\sigma_{v}(x)$ - vertical stress at the $(x)$ distance from lining in the analyzed reinforcement layer.

The most common load combinations which are taken into account while controlling internal stability of reinforced soil structure as well as partial safety factors $\left(\gamma_{m}\right)$ are presented in the tables of NF P 94-200 [1, 3] standard.

Real friction factor $\mu^{*}$ is a relationship of cutting down stress to the mean vertical stress, which means that it depends on the depth of reinforcement location in the soil mass.

Safety control of each reinforcement layer with regard to break consists in determination whether two inequalities are fulfilled (considering the method factor as well as the partial safety factor with regard to reinforcement layer break):

- maximal stretching forces in the reinforcement layer are smaller than characteristic resistance of the reinforcement layer,

- maximal stretching stress at the structure lining is smaller than characteristic resistance of the reinforcement layer combined with the lining.

The partial safety factor with regard to the reinforcement layer break appears here and is assumed as 1.50 for standard structures and as 1.65 - for special ones (that means such, whose repairs will cause financial losses not acceptable for the user).

In each reinforcement layer and, when it is necessary also in the maximal stretching line, the stretching stress should be less than the value of characteristic friction mobilized in each reinforcement layer, while applying factor of method and partial safety factor for anchoring of reinforcement, assumed as 1.20 in case of standard structures and as 1.30 - for special structures.

It should also be controlled whether characteristic resistance of the lining is higher than maximal stretching stress at the lining (using the method factor and partial safety factor, assumed as 1.65 in case of concrete linings and as 1.50 - for metal linings).

\section{Control of general stability}

All potential soil destruction surfaces are taken into account as well as prevention of slides due to their cutting down resistance along these surfaces and increase of soil stability with the reinforcement layers cut by destruction surfaces. In case of uniform soil a potential destruction surface is usually cylindrical in form (Fig. 4). 


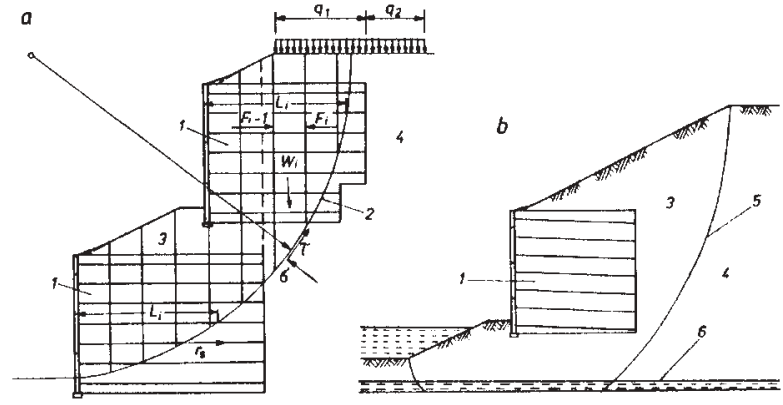

Fig. 4. Schemes of general stability control [1]: a - destruction along cylindrical surface, $b$ - special case of destruction; 1 - reinforced soil mass, 2 - circular line of soil destruction, 3 - destruction zone,

4 - zone outside the destruction area, 5 - non-circular line of soil destruction, 6 - weak base layer

When a heavy structure is supported by reinforced soil mass, one of possible destruction forms is a wedge-shaped fragment including also this structure.

The maximal stretching value mobilized inside the reinforcement at the section with destruction surface is limited by:

- soil-reinforcement friction, which might be mobilized outside this surface,

- stretching resistance of the reinforcement bars,

- lining resistance at its joints with reinforcement, increased by friction value along the reinforcing elements, mobilized between the joints with the lining and the analyzed destruction surface.

Participation of soil reinforcement in the maintenance of general stability of the structure is expressed by $F_{R}$ forces present in each reinforcement layer cut by destruction surface.

The designed soil resistance to cutting down $\tau_{d}$ along the destruction surface, at its each point, is calculated according to the following formula:

$$
\tau_{d}=c_{d}+\sigma_{n} \operatorname{tg} \varphi_{d} \quad[\mathrm{kPa}]
$$

in which:

$c_{d}, \varphi_{d}$ - computational values of cutting down resistance parameters: cohesion, internal friction angle [ $\mathrm{kPa}$, degrees],

$\sigma_{n} \quad$ - normal stress in the soil in relation to destruction surface $[\mathrm{kPa}]$.

A number of destruction surfaces should be analyzed, usually with Bishop's method. In case of each method a general balance should be controlled using equations and moments and vertical forces. While applying the band method without analysis of balance of horizontal forces then reciprocal influence forces of bands in horizontal direction shall be adopted.

The stresses $\sigma_{n}$ calculated according to the above formula have values different from the ones obtained in case of lack of reinforcement. This is caused by the influence of reinforcement bars anchored at both sides of destruction surface.

A general stability analysis should consider all potential load combinations: standard and random.

The binding partial safety parameters for control of general stability and load combinations are given in the standard tables [3].

\section{Stability control with regard to subsoil load capacity}

This control is realized basing on the evaluation of deformations' values, which will appear after the building of a structure of reinforced soil. Generally, such structures are characterized by increased flexibility, however, when great deformations are present they may negatively influence structures supported on the reinforced mass or located in its close proximity. Deformation causes might be of internal or external character (subsoil settlement or consolidation). Reinforcement bars are practically inextensible, and that is why designs take into account only external causes. Determination of settlements has a purpose of proving that deformations caused by them will fit the permissible range for buildings supported on the reinforced soil structures and remaining within the reach of subsoil deformation influence. Only combinations of constant and almost constant loads are considered in calculations. The values of partial safety factors ( $\mathrm{m}$ used in these calculations are stated in the standard tables [3].

\section{Conclusion}

The principles of designing retaining structures of the reinforced soil with limit conditions method, elaborated in the French standard NF P 94-200 were discussed. The computation scheme of the structure was given in which the standard assumes a broken line of maximal stretching in the reinforcement as well as distribution of stretching forces' values according to the principles of the reinforced soil classics (H. Vidal, F. Schlosser [2, 5, 6]. A special emphasize should be put on the load combinations proposed for consideration by the standard [3] (deadweight, moving load, soil backfill pressure) as well as partial safety factors of the external, internal and general stability and: method factors, partial factors of settlement safety and values of soil medium-reinforcement friction for some cases of reinforcement bars. It seems worthwhile to confront resolutions of the French standard with Polish standard [4] with regard to its possible modification.

\section{References}

[1] JAROMINIAK, A.: Light retaining structures (Lekkie konstrukcje oporowe), Wkit, Warsaw 1999.

[2] LONG, N.T., SCHLOSSER, F.: Dimensioning of reinforced soil walls (Wymiarowanie murów z gruntów zbrojonych), Selected Problems of Geotechnics (Wybrane Zagadnienia Geotechniki), PAN-IBW, Wrocław, Ossolineum, 1978, s. 211-237. 
[3] NFP 94-200: Reinforcement des sols par inclusions. Ouvrages en sols rapportes renforces par armatures ou nappes peu extensibles et souples. Dimensionnement.

[4] PN 83/B-03010: Retaining walls (Ściany oporowe). Static calculations and design (Obliczenia statyczne i projektowanie), PN 83/B03010, 1983.

[5] SCHLOSSER, F.: La terre armee', historique development, actuel et futur. Proc. Symp. Soil Reinforcing and Stabilising Techq., NSWIT/NSW Univ., 1978, s. 5-28.

[6] SCHLOSSER, F.: Reinforced Soil in Civil Engineering (in Polish). Archiv. Hydrotechn., Vol. XXI, No. 2, pp. 299-336, 1974. 